\title{
Comparison of amino acid $v$ peptide based enteral diets in active Crohn's disease: clinical and nutritional outcome
}

\author{
D Royall, K N Jeejeebhoy, J P Baker, J P Allard, F M Habal, S C Cunnane, G R Greenberg
}

\begin{abstract}
Elemental diets are considered an effective primary treatment for active Crohn's disease. This study examined the hypothesis that improvement occurs because of the presence of amino acids or the low fat content, or both. $A$ randomised, controlled trial was undertaken in 40 patients with active Crohn's disease to evaluate clinical and nutritional outcomes after an amino acid based diet containing 3\% fat was given by a feeding tube compared with a peptide based diet containing $33 \%$ fat. After three weeks' treatment, clinical remission occurred in $84 \%$ of patients who were given the amino acid diet and $75 \%$ of patients who received the peptide diet $(p=0 \cdot 38)$. Plasma linoleic acid concentration was reduced after the amino acid but not the peptide diet. An increase in total body nitrogen was associated with the magnitude of nutritional depletion before treatment and at six months' follow up, only patients who showed gains in total body nitrogen after enteral nutrition had a sustained clinical remission. This study shows that peptide based high fat diets are as effective as amino acid low fat diets for achieving clinical remission in active Crohn's disease. Improved total body protein stores but not essential fatty acid depletion may be an important indicator of a sustained remission.

(Gut 1994; 35: 783-787)
\end{abstract}

Enteral nutritional support has been shown to be an effective treatment for the symptomatic management of patients with acute Crohn's disease. ${ }^{1-5}$ Although the precise mechanisms whereby improvement occurs are unclear, recent studies show that the provision of nutritional support rather than bowel rest is the predominant factor contributing to clinical remission. ${ }^{67}$ The optimal composition of enteral diets to induce clinical remission has not been determined. Comparison between enteral diets having different sources of nitrogen has yielded inconclusive results. Some $^{8}$ but not all ${ }^{9-11}$ studies have reported that elemental (amino acid based) diets were more effective than whole protein based diets for inducing clinical remission. Fat composition may also be a relevant factor as recent studies performed in experimental animals suggest that enteral diets high in linoleic acid increase leukotriene concentrations but diets low in linoleic acid reduce inflammation. ${ }^{12}{ }^{13}$ Elemental but not polymeric diets are low in fat content but the effects of either type of diet on fatty acid profiles and their relation to clinical outcome has not been quantified.
In malnourished patients with Crohn's disease a further goal of nutritional support is anabolic recovery because it is believed but not proved, that the magnitude of nutritional repletion is one factor influencing clinical remission. Enteral diets with protein as short chain peptides have been suggested to be preferred to amino acid ${ }^{14}$ or whole protein ${ }^{15}$ mixtures as the source of nitrogen. Direct assessment of lean body mass or body nitrogen after enteral nutritional support has not been studied, however, these parameters are maintained but not improved after administration of total parenteral nutrition in active Crohn's disease patients. ${ }^{1617}$

Therefore, a prospective, controlled study was undertaken to assess the clinical and the nutritional outcome, including measurement of total body nitrogen to provide an accurate assessment of body composition changes over time ${ }^{18}$ and fatty acid profiles of patients with active Crohn's disease who were treated with either an elemental, amino acid based diet very low in long chain triglycerides (3\% of energy), compared with a peptide based diet with a higher long chain triglyceride content (10\% of energy) and also containing substantial amounts of medium chain triglycerides ( $23 \%$ of energy).

\section{Methods}

\section{PATIENTS}

Forty patients with Crohn's disease diagnosed by established radiological or endoscopic findings, or both participated in the study. Entry into the trial was restricted to patients with moderate to severely active Crohn's disease affecting the small bowel or colon, or both as defined by a minor modification of the Crohn's disease activity index (CDAI) described previously, ${ }^{19}$ of greater than 250. Reasons for exclusion of patients from the study were: (a) treatment at entry with prednisone $>15 \mathrm{mg} / \mathrm{d}$, (b) treatment with other immunosuppressive drugs, and (c) unwillingness to give informed consent or to accept tube feeding. Each patient provided written, informed consent and the study protocol was approved by the ethics committee of each institution and by the University of Toronto human subjects review committee.

\section{EXPERIMENTAL DESIGN}

Patients were randomised (using random number tables) in a double blind fashion to one of two nutritional support groups treated in hospital for 21 days. The blinding was assured by the fact that diets were premixed by the dietetic 
department, coded, and appeared the same in the cartons sent to the ward. Both the patient and the evaluating persons were blinded. The enteral diets were given throughout a 24 hour period through a nasoduodenal feeding tube (Silk Enteral Feeding Tube, Corpak, Inc, Wheeling, IL) placed fluoroscopically so that the tip was at the ligament of Treitz. The nutritional objectives were to achieve an intake over 24 hours of 35 non-protein $\mathrm{kcal} / \mathrm{kg}$ ideal body weight (IBW, defined on the basis of a body mass index (BMI) of $23 \mathrm{~kg} / \mathrm{m}^{2}$ ) and $1 \mathrm{~g} / \mathrm{kg}$ IBW of protein. The feedings were gradually progressed to full strength over the first three days by adjusting the flow rate to provide $50 \%$ of total estimated volume to meet energy requirements over day $1,75 \%$ over day 2 , and thereafter at $100 \%$ of required volume.

The two nutritional groups included an amino acid based defined formula diet (Vivonex-TEN, Sandoz Nutrition, Minneapolis, MN) and a peptide based defined formula diet (Peptamen, Clintec Nutrition, Chicago, IL). Both diets had the sodium content increased to $100 \mathrm{mmol} / \mathrm{l}$ by the addition of $5 \mathrm{~g} \mathrm{NaCl}$ (table salt) to each litre of the diet, which may decrease the frequency of enteral feeding associated diarrhoea. ${ }^{20}$ Additional fluid and electrolyte requirements were met by giving $0.9 \%$ normal saline plus electrolytes through a peripheral intravenous infusion at the discretion of the attending physician. Sips of water were permitted ad libitum, but no other food or beverage was permitted. All drugs were discontinued with the exception of prednisone, which was maintained at a median dose of $10 \mathrm{mg}$ (range 5-15 mg) daily in the 17 patients receiving this drug at entry.

\section{EVALUATION OF CLINICAL RESPONSE}

Radiological, endoscopic, and histological data were obtained before entry into the trial. Clinical, nutritional, and biochemical data were obtained before entry and at day 21 . The severity of the Crohn's disease was assessed by the Crohn's disease activity index (CDAI) where a score greater than 300 indicated severe disease activity, a score between 150 and 299 indicated moderate activity, and a score less than 150 , little or no activity. Patients were monitored on a daily basis with a detailed CDAI performed before entry and weekly throughout the trial. Biochemical parameters of inflammation included $\alpha$-1-acid-glycoprotein and $C$ reactive protein measured by standardised automated techniques.

A full clinical remission was defined as a CDAI of less than 150 by day 21 of treatment and the subsequent maintenance of a full oral diet without an increase in CDAI, drugs, or surgery. The trial was terminated if at least two physicians (attending physician and a physician who did not participate in primary care) independently concluded that one of the following criteria were met: (a) continuing the trial was hazardous for any reason; (b) a progressive increase in CDAI of greater than 100 occurred by the end of the first week of treatment; (c) there was no improvement in CDAI after two weeks of treatment; (d) there was significant pain or vomiting over any three consecutive days; or (e) the mean energy intake after seven days did not achieve $2000 \mathrm{kcal} /$ day.

All patients considered to have undergone remission were discharged from hospital and followed up at 1, 3, 6, and 12 months. A relapse was defined as: (a) a CDAI rising to greater than 250 with an inability to maintain a full oral diet or (b) complications requiring an increase in corticosteroids, alternate drug treatment or surgery, or both.

\section{NUTRITIONAL ASSESSMENT}

Albumin and transferrin were measured by standardised automated techniques. For phospholipid analysis, plasma was stored in chloroform containing $0.02 \%$ butylated hydroxytoluene as an antioxidant, in an oxygen free environment at $-70^{\circ} \mathrm{C}$ and analysed as previously described. ${ }^{21}$

Body weight was taken weekly and total body nitrogen was assessed before the start of treatment and after three weeks of enteral nutrition. Total body nitrogen was analysed by prompt gamma technique. ${ }^{22}$ Total body protein was calculated from total body nitrogen assuming that all nitrogen in the body is in protein, of which it forms $16 \%$. A nitrogen index was calculated from total body nitrogen, which normalises body nitrogen for body size and makes possible the estimation of the protein state in individual patients. The mean nitrogen index in healthy subjects is 1.0 and a nitrogen index $<0.85$ ( 2 SD below the mean) reflects subnormal body nitrogen. ${ }^{23}$

\section{STATISTICAL ANALYSIS}

All results are expressed as mean (SEM). Split plot repeated measures analysis of variance was used for the assessment of changes in CDAI and nutritional parameters between groups. Student's $t$ test (paired) was used to determine the significance of changes of values within patients. Fisher's exact test was used to test for differences in clinical response between groups. Step wise multiple regression analysis was performed to determine the comparative contribution of factors influencing nutritional response. Significance of differences in relapse rates between groups was determined by life table analysis.

\section{Results}

\section{CLINICAL FEATURES OF TREATMENT GROUPS}

Forty patients with active Crohn's disease, 17 women and 23 men were admitted to the trial. Nineteen patients received the amino acid based diet and 21 patients were provided the peptide based diet. Table I shows that at entry, the two groups were comparable as regards clinical and nutritional parameters. One patient entered into the peptide based group voluntarily withdrew after five days because of a family mishap unrelated to the feeding. Thus, 19 patients in the amino acid based group and 20 patients in the peptide based group were evaluated for response to treatment. 
TABLE I Clinical parameters at entry ${ }^{\star}$

\begin{tabular}{lcc}
\hline & $\begin{array}{l}\text { Amino acid } \\
\text { based }\end{array}$ & $\begin{array}{l}\text { Peptide } \\
\text { based }\end{array}$ \\
\hline Number $(\mathrm{M} / \mathrm{F})$ & $19(10 / 9)$ & $21(13 / 8)$ \\
Age $(\mathrm{y})$ & $31 \cdot 5(3 \cdot 4)$ & $31 \cdot 4(2 \cdot 6)$ \\
$\mathrm{BMI}\left(\mathrm{kg} / \mathrm{m}^{2}\right)$ & $19 \cdot 7(0 \cdot 8)$ & $21 \cdot 0(0 \cdot 7)$ \\
Disease duration $(\mathrm{y})$ & $9 \cdot 5(2 \cdot 2)$ & $6 \cdot 8(1 \cdot 4)$ \\
Prednisone dose $(\mathrm{mg} / \mathrm{day})$ & $11 \cdot 7(1 \cdot 1)$ & $13 \cdot 2(1 \cdot 0)$ \\
Previous resections $(\mathrm{n})$ & $0 \cdot 8 \pm 0 \cdot 3$ & $1 \cdot 4(0 \cdot 5)$ \\
Disease extent $\dagger$ & 5 & 11 \\
$\quad$ Small bowel & 12 & 8 \\
$\quad$ Small bowel +colon & 2 & 2 \\
$\quad$ Colon & 4 & 7 \\
Fistulas & 4 & 4 \\
Inflammatory mass $\dagger$ & $343(20)$ & $360(12)$ \\
Initial CDAI & & \\
\hline
\end{tabular}

^ No significant differences were present between groups;

† Values show number of patients with this feature present.

Values expressed as mean (SEM).

\section{CLINICAL RESPONSES TO ENTERAL NUTRITION}

Outcome after three weeks' treatment - after three weeks of enteral nutritional support, remission rates were equivalent between the two groups: 16 patients $(84 \%)$ responded to the amino acid based diet and 15 patients (75\%) after receiving the peptide based diet $(\mathrm{p}=0 \cdot 38)$. Although all patients did not complete three weeks of treatment because of early failure, the reductions in CDAI in those patients available for analysis were also equivalent in the two groups $(\mathrm{p}<0.0005)(\mathrm{Fig} 1)$ as were the reductions of $\alpha$-1-acid-glycoprotein and $C$ reactive protein (Table II). No differences in outcome could be attributed to coadministration of corticosteroids; the reductions in CDAI at three weeks in corticosteroid treated $(\triangle=202(29) ; n=15)$ and corticosteroid free $(\triangle=252(24) ; n=16)$ patients
Figure 1: Mean (SEM) $C D A I$ over three weeks of amino acid (left) and peptide based (right) enteral treatment.

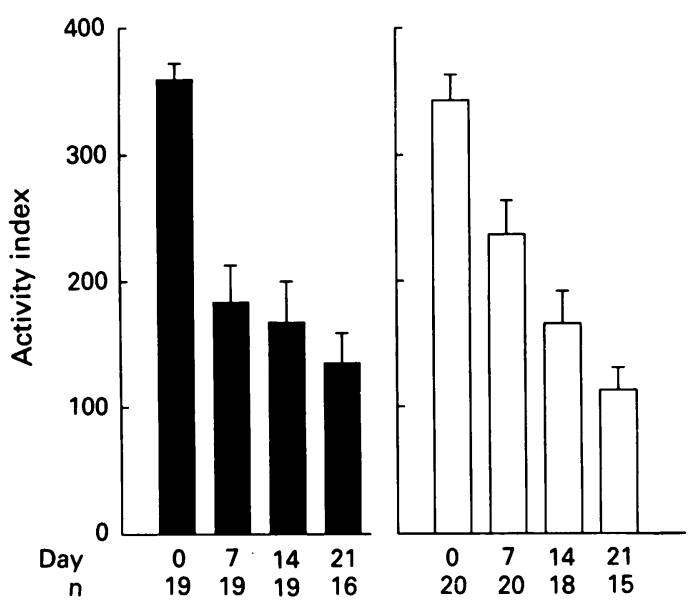

TABLE II Biochemical and nutritional data at entry and after three weeks of treatment

\begin{tabular}{|c|c|c|c|c|}
\hline & \multicolumn{2}{|c|}{ Amino acid based } & \multicolumn{2}{|l|}{ Peptide based } \\
\hline & Day 0 & Day 21 & Dayo & Day 21 \\
\hline $\operatorname{AAG}(g / \mathbf{l})$ & $1.5(0.2)$ & $1 \cdot 1(0 \cdot 1) \ddagger$ & $1 \cdot 6(0 \cdot 2)$ & $1 \cdot 1(0 \cdot 1) \ddagger$ \\
\hline $\mathrm{CRP}(\mathrm{mg} / \mathrm{l})$ & $12 \cdot 3(3 \cdot 5)$ & $7 \cdot 1(2 \cdot 0)$ & $14 \cdot 3(5 \cdot 1)$ & $4.6(1.6)^{\star}$ \\
\hline Weight (kg) & $57 \cdot 2(3 \cdot 6)$ & $58 \cdot 8(3.6) \S$ & $58 \cdot 9(3 \cdot 2)$ & $60 \cdot 9(3 \cdot 1) \rrbracket$ \\
\hline Albumin $(\mathrm{g} / \mathrm{l})$ & $36(1)$ & $34(2)$ & $38(1)$ & $38(1)$ \\
\hline Transferrin (g/l) & $2 \cdot 0(0 \cdot 2)$ & $2 \cdot 5(0 \cdot 2)^{\star}$ & $2 \cdot 5(0.2)$ & $3 \cdot 1(0 \cdot 2) \dagger$ \\
\hline $\mathrm{TBN}(\mathrm{kg})$ & $1.44(0.10)$ & $1.52(0.11) t$ & $1.55(0.09)$ & $1.56(0.09)$ \\
\hline NI & $0.81(0.03)$ & $0.84(0.03) \dagger$ & $0.84(0.04)$ & $0.84(0.03)$ \\
\hline \multirow{5}{*}{$\begin{array}{l}\text { Total phospholipids (mg/ml) } \\
\text { \% Composition } \\
18: 0 \\
18: \ln -9\end{array}$} & $1 \cdot 23(0 \cdot 11)$ & $1.22(0.08)$ & $1 \cdot 37(0 \cdot 10)$ & $1.71(015) \dagger$ \\
\hline & $11 \cdot 6(1 \cdot 1)$ & $10 \cdot 4(0 \cdot 8)$ & $10 \cdot 6(1 \cdot 0)$ & $10 \cdot 2(1 \cdot 1)$ \\
\hline & $12.5(0.9)$ & $14.3(0.7)^{\star}$ & $10.7(0.5)$ & $8 \cdot 8(0.6) \ddagger$ \\
\hline & $21 \cdot 0(1 \cdot 5)$ & $16 \cdot 5(1 \cdot 2) \ddagger$ & $24.4(0.9)$ & $25 \cdot 6(1 \cdot 2)^{+}$ \\
\hline & $12 \cdot 4(0 \cdot 6)$ & $11.4(0.5)$ & $14 \cdot 2(1 \cdot 1)$ & $11 \cdot 6(1 \cdot 3)$ \\
\hline
\end{tabular}

When compared with day $0:{ }^{\star} p<0.05 ; \mathrm{p}<<0.025 ; \neq \mathrm{p}<0.01 ; \S \mathrm{p}<0.0005$

AAG $=\alpha$-1-acid-glycoprotein; $\mathrm{CRP}=\mathrm{C}$ reactive protein, $\mathrm{TBN}=$ total body nitrogen; $\mathrm{NI}=$ nitrogen index. Values expressed as mean (SEM).

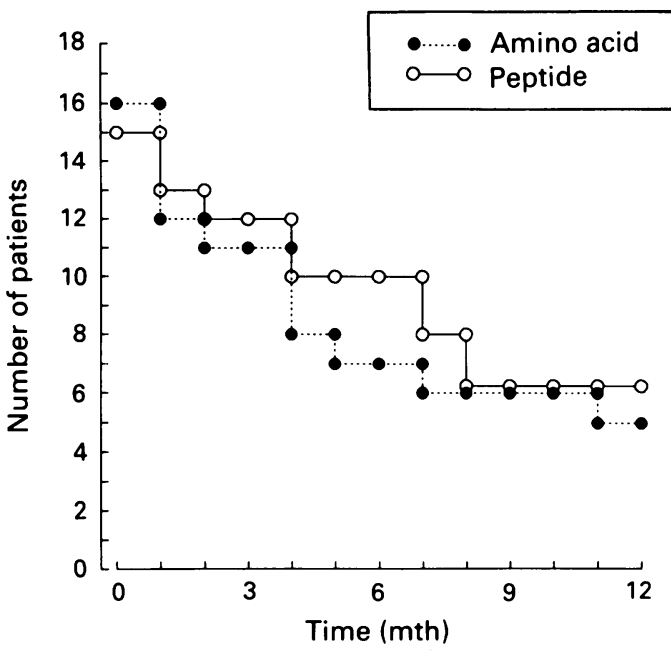

Figure 2: Relapse over 12 months after discharge in patients responding to amino acid and peptide based enteral nutrition.

were similar, as were the decrements of $\alpha$-1-acidglycoprotein and $C$ reactive protein $(7 \cdot 4$ $(2 \cdot 4) \mathrm{mg} / \mathrm{l} v 7 \cdot 2(2 \cdot 6) \mathrm{g} / \mathrm{l})$. Of the three patients not responding to the amino acid based diet, one patient responded to increased doses of corticosteroids and the other two patients required surgery. Of the five patients not responding to the peptide based diet, three patients were treated medically (one responded to corticosteroids, one to total parenteral nutrition, and one to another elemental diet) and the other two patients required surgery. None of the patients developed any septic or metabolic complications that could be directly attributable to the enteral nutritional treatment.

Outcome upon 12 months' follow up - the outcome in patients responding to nutritional treatment indicated relapse rates over time that were equivalent between the two groups (Fig 2). At 12 months, remission was sustained in $31 \%$ of patients who received the amino acid based diet and $40 \%$ of patients who received the peptide based diet $(p=0 \cdot 39)$. Thus, of the 39 patients who entered the trial, 18 patients $(46 \%)$ required surgery, 10 patients $(26 \%)$ required additional medical treatment, and 11 patients $(28 \%)$ had a sustained remission. The entry parameters of patients with a sustained remission at 12 months when compared with patients who relapsed showed no significant differences between successes and failures (Table III).

TABLE III Entry parameters of patients with remission and relapse at one year follow $u p^{\star}$

\begin{tabular}{lcc}
\hline & Remission & Relapse \\
\hline Number $(\mathrm{M} / \mathrm{F})$ & $11(8 / 3)$ & $20(10 / 10)$ \\
BMI $\left(\mathrm{kg} / \mathrm{m}^{2}\right)$ & $19 \cdot 0(0 \cdot 7)$ & $20 \cdot 8(0 \cdot 8)$ \\
Prednisone $(n)$ & $6(55 \%)$ & $9(45 \%)$ \\
Prednisone dose $(\mathrm{mg})$ & $10 \cdot 8(1 \cdot 5)$ & $13 \cdot 3(0 \cdot 8)$ \\
Disease extent $\dagger$ & & \\
$\quad$ Small bowel & $6(55 \%)$ & $9(45 \%)$ \\
Smal bowel +colon & $5(45 \%)$ & $9(45 \%)$ \\
Colon & 0 & $2(10 \%)$ \\
Fistulas & $3(27 \%)$ & $6(30 \%)$ \\
Initial CDAI & $360(17)$ & $343(13)$ \\
Albumin $(\mathrm{g} / \mathrm{l})$ & $36(2)$ & $37(1)$ \\
AAG $(\mathrm{g} / \mathrm{l})$ & $1 \cdot 6(0 \cdot 2)$ & $1 \cdot 6(0 \cdot 2)$ \\
CRP $(\mathrm{mg} / \mathrm{l})$ & $8 \cdot 1(3 \cdot 4)$ & $16 \cdot 3(4 \cdot 2)$ \\
& &
\end{tabular}

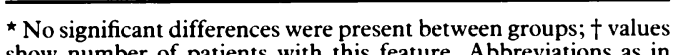
show number of patients with this feature. Abbreviations as in Table II. Values expressed as mean (SEM). 
NUTRITIONAL RESPONSES TO ENTERAL NUTRITION The average non-protein energy intake, which exceeded $2100 \mathrm{kcal} /$ day and the protein intake (amino acid based: $62(2) \mathrm{g} / \mathrm{d} v$ peptide based: 60 (2) $\mathrm{g} / \mathrm{d}$ ) were similar in the two groups. After three weeks of treatment, weight gain in the amino acid based $(1 \cdot 7(0.3) \mathrm{kg})$ and peptide based $(2.0(0.5) \mathrm{kg})$ groups was equivalent (both $\mathrm{p}<0.0005)$, as were plasma concentrations of transferrin and albumin (Table II).

Body composition - upon entry, patients had lost, on average, $10.6 \mathrm{~kg}$ or $15 \%$ of body weight and, when compared with a group of healthy age and sex matched subjects from our laboratory, a $2.2 \mathrm{~kg}$ or $19 \%$ loss of protein. At baseline, total body nitrogen and nitrogen index seemed lower in the amino acid based compared with the peptide based group, but the difference was not significant (Table II). After three weeks of enteral nutrition, total body nitrogen and nitrogen index increased after the amino acid based diet and not the peptide based diet (Table II) but the only factor accounting for this difference in total body nitrogen was the magnitude of nutritional depletion. At three weeks, $\triangle$ total body nitrogen was significantly negatively correlated with the initial nitrogen index $(r=-0.43, \mathrm{p}<0.025)$ (Fig 3) but not to diet type $(\mathrm{p}=0.30)$ or to administration of prednisone $(\mathrm{p}=0.55)$. The overall gain in total body nitrogen was $3.1(1.5) \%(\mathrm{p}<0.025$ compared with baseline) representing a net increase of 286 (131) g total body protein.

Plasma phospholipids - plasma phospholipid concentration increased significantly after three weeks' treatment with the peptide based diet but did not change with the amino acid based diet (Table II). The important change in the per cent fatty acid composition of phospholipids was a fall in linoleic acid (18.2 n-6) with the amino acid based diet, which did not occur on the peptide based diet. The composition of linoleic acid in serum triglycerides showed similar changes to those seen in phospholipids (data not shown).

Relation of nutritional response to longterm outcome - nutritional responses to enteral therapy influenced maintenance of remission. At six months' follow up, 17 patients with a sustained clinical remission showed a significant gain in total body nitrogen $(\triangle=80.6(30.6) \mathrm{g} ; \mathrm{p}<0.01)$ after three weeks of nutritional therapy but 14 patients who relapsed showed no change in total body nitrogen $(\triangle=0 \cdot 1(22 \cdot 9) \mathrm{g} ; \mathrm{p}=0 \cdot 46)$.

Figure 3: Correlation between the change in total body nitrogen (TBN) and initial nitrogen index after three weeks of enteral nutrition.
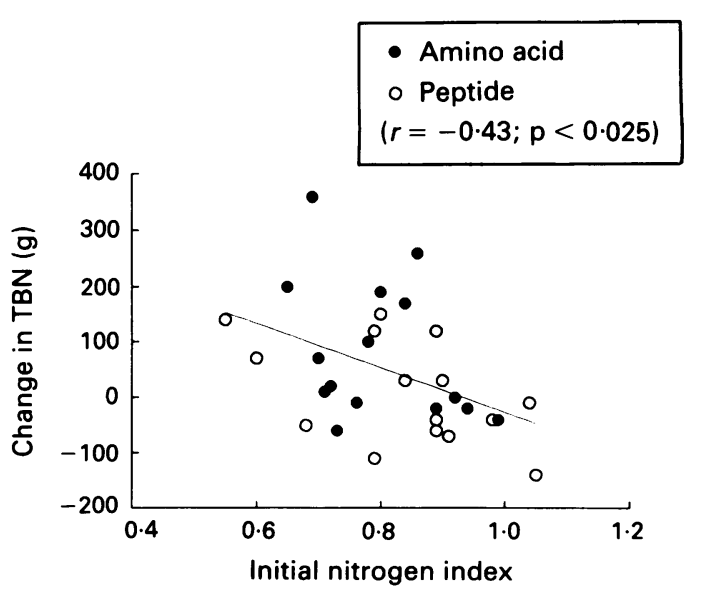

\section{Discussion}

Determination of the optimum enteral formulation required to induce clinical remission in acute Crohn's disease has been the subject of some controversy ${ }^{24}$ because controlled evaluation has been performed in a limited number of trials $^{8-11}$ and with variable results. The results of this randomised, controlled trial show that $75 \%$ to $84 \%$ clinical remission can be induced in severely active Crohn's disease by an amino acid based or peptide based elemental diet given over a three week period. These remission rates are comparable with the studies other investigators have reported comparing elemental diets with prednisone. ${ }^{325} 26$

Clinical remission rates were, however, higher than the $53 \%$ remission reported by Lochs et al $^{27}$ in a trial comparing a peptide based enteral feeding with standard medical treatment. Disease severity was comparable in both populations and the same criteria for evaluation of response was used in both studies. Moreover, in our study, objective improvement was shown by the reductions of serum $\alpha$-l-acid-glycoprotein and $\mathrm{C}$ reactive protein concentration after both forms of enteral feeding. Therefore, the reason for these different results was not initially apparent. One additional factor, however, that also influenced outcome after nutritional treatment in our study was the improvement of. nutrition as shown by a gain in total body nitrogen. Patients who showed increases in total body nitrogen after three weeks of enteral nutrition, had a sustained remission at six months' follow up when compared with those patients with unchanged total body nitrogen all of whom relapsed at six months' follow up. It is noteworthy from the trial by Lochs et $a l^{27}$ that patients who did not respond to either diet or drug treatment also showed no gain in body weight, whereas responders to both forms of treatment showed substantial weight gain. Similar findings were made in another study ${ }^{10}$ comparing elemental and polymeric enteral diets where increases in body weight and creatinine index were associated with clinical remission. Thus, the measurement of the magnitude of nutritional repletion may be an important factor in the assessment of clinical remissions after nutritional (or drug) treatment.

Upon one year follow up, about two thirds of the patients in each group had relapsed. This relapse rate is somewhat greater than the $45 \%$ relapse we saw in a prospective study of Crohn's patients treated with an enteral diet. ${ }^{6}$ Forty six per cent of patients who entered the trial ultimately required surgery, which is perhaps a reflection of the disease severity in the patient population presently studied. Few other prospective, controlled studies report one year follow up after enteral nutrition; higher relapse rates were reported by Park et al, ${ }^{11}$ whereas Rigaud et $a l^{10}$ reported results similar to our findings. Although several of our patients had fistulous disease and inflammatory masses, these features did not significantly affect outcome after the two types of enteral treatment, nor did the initial values of various laboratory tests, including values of inflammatory mediators.

Independent of the source of nitrogen in the 
diets, the patient's initial nutritional state was the important factor determining the gain in total body nitrogen. Nutritionally depleted patients showed greater repletion of total body nitrogen while well nourished patients maintained their initial values of nitrogen. Overall, we have shown an increase in body weight after enteral nutrition and it is noteworthy that body composition analysis showed that about $300 \mathrm{~g}$ of this weight gain comprised total body protein. These results contrast with reported findings after parenteral nutrition infusion. Christie $e t a l^{17}$ showed in patients with acute inflammatory bowel disease receiving parenteral nutrition, that early improvements occurred in physiological function (respiratory and skeletal muscle function) but there was no rise in total body protein. To our knowledge, our study is the first that has assessed total body nitrogen after enteral nutrition treatment in Crohn's disease and the results suggest an important role of enteral nutrition for maximising anabolic repletion.

Recent experimental studies in animals have shown that enteral diets inducing linoleic acid deficiency exert an anti-inflammatory effect by inhibiting eicosanoid generation..$^{12}$ In this study, the fall in per cent composition of linoleic acid in phospholipids that occurred after three weeks' treatment with the amino acid diet, shows a reduction in linoleic acid stores. Patients receiving $2000 \mathrm{kcal} /$ day would receive about $5 \mathrm{~g}$ linoleic acid/day on the amino acid diet compared with $15 \mathrm{~g}$ linoleic acid/day on the peptide diet. As clinical outcome and inflammatory mediators were comparable after three weeks with the two diets, the anti-inflammatory benefits of elemental diets cannot be attributed to their very low polyunsaturated fatty acid content.

In conclusion, this study has shown that after three weeks of enteral nutrition, peptide based diets are as efficacious as amino acid based diets in inducing a high rate of clinical remission. Reduction in plasma linoleic acid did not increase the remission rate. Improved total body nitrogen was associated with prolonged remission suggesting that future studies should include examination of the manner by which body protein stores can be maximised that may, in turn, contribute to long lasting remission.

This work was supported, in part, by a grant from Clintec Nutrition Co.

1 Gassull MA, Abad A, Cabre E, Gonzales-Huix F, Gine JJ, Dolz C. Enteral nutrition in inflammatory bowel disease. Dolz C. Enteral nutrition in

2 Teahon K, Bjarnason I, Pearson M, Levi AJ. Ten years' experience with an elemental diet in the management of Crohn's disease. Gut 1990; 31: 1133-7.

3 O'Morain C, Segal AW, Levi AJ. Elemental diet as primary treatment of acute Crohn's disease: a controlled trial. $B M \mathcal{Y}$ 1984; 288: 1859-62.
4 Saverymuttu S, Hodgson HJF, Chadwick VS. Controlled trial comparing prednisolone with an elemental diet plus nonabsorbable antibiotics in active Crohn's disease. Gut 1985; 26: $994-8$.

5 Okada M, Yao T, Yamamoto T, Takenaka K, Imamura K, Maeda $\mathrm{K}$, et al. Controlled trial comparing an elemental diet Maeda K, et al. Controlled trial comparing an elemental diet with prednisolone in the treatment of activ
Hepatogastroenterology 1990; 37: 72-80.

6 Greenberg GR, Fleming CR, Jeejeebhoy KN, Rosenberg IH Sales D, Tremaine WJ. Controlled trial of bowel rest and nutritional support in the management of Crohn's disease. Gut 1988; 29: 1309-15.

7 Lochs H, Meryn S, Marosi L, Ferenci P, Hortnag H. Has total bowel rest a beneficial effect in the treatment of Crohn's disease? Clin Nutr 1983; 2: 61-4.

8 Giaffer MH, North G, Holdsworth CD. Controlled trial of polymeric versus elemental diet in treatment of active Crohn's disease. Lancet 1990; 335: 816-9.

9 Raouf AH, Hildrey V, Daniel J, Walker RJ, Krasner N, Elias $\mathrm{E}$, et al. Enteral feeding as sole treatment for Crohn's disease: controlled trial of whole protein $\mathrm{v}$ amino acid based feed and a case study of dietary challenge. Gut 1991; 32: feed an

10 Rigaud D, Cosnes J, Le Quintrec Y, Rene E, Gendre JP, Mignon M. Controlled trial comparing two types of enteral nutrition in treatment of active Crohn's disease: elemental v polymeric diet. Gut 1991; 32: 1492-7.

11 Park RHR, Galloway A, Danesh BJZ, Russell RI. Doubleblind controlled trial of elemental and polymeric diets as primary therapy in active Crohn's disease. Eur $\mathcal{f}$ Gastroento Hepatol 1991; 3: 483-90.

12 Lefkowith JB. Essential fatty acid deficiency inhibits the in vivo generation of leukotriene B4 and suppresses levels of resident and elicited leukocytes in acute inflammation. I Immunol 1988; 140: 228-33.

13 Lohoues MJ, Russo P, Gurbindo C, Roy C, Levy E, Lepage G et al. Essential fatty acid deficiency improves the course of experimental colitis in the rat: possible role of dietary immunomodulation. Gastroenterology 1992; 102: A655.

14 Silk DBA, Fairclough PD, Clark ML, Hegarty JE, Marrs TC Addison JM. Uses of a peptide rather than a free amino acid nitrogen source in chemically defined elemental diets. PEN 1980; 4: 548-53.

15 Rees RGP, Hare WR, Grinble GK, Frost PG, Silk DPA. Do patients with moderately impaired gastrointestinal function requiring enteral nutrition need a predigested nitrogen source? A prospective crossover controlled clinical trial. Gut 1992; 33: 877-81.

16 Jacobson S, Carlmark B. Total body potassium, fat and water during total parenteral nutrition in Crohn's disease. Clin Nutr 1990; 9:272-80.

17 Christie PM, Hill GL. Effect of intravenous nutrition on nutrition and function in acute attacks of inflammatory bowel disease. Gastroenterology 1990; 99: 730-6.

18 Jensen MD. Research techniques for body composition assessment. F Am Diet Assoc 1992; 92: 454-60.

19 Ostro MJ, Greenberg GR, Jeejeebhoy KN. Total parenteral nutrition and complete bowel rest in the management of Crohn's disease. $\mathcal{F P E N} 1985 ; 9: 280-7$.

20 Halpern ML, Wolman SL, Greenberg GR. Paracellular recirculation of sodium is essential to support nutrient absorption in the gastrointestinal tract: an hypothesis. Clin Invest Med 1986; 9: 209-11.

21 Cunnane SC. The profile of long chain fatty acids in serum phospholipids: a possible indicator of copper status in phospholipids: a possible indicator of cop

22 Mernagh J, Harrison JE, McNeill KG. In vivo determination of nitrogen using Pu-Be sources. Phys Med Biol 1977; 22 $831-5$.

23 Harrison JE, McNeill KG, Phil D, Strauss AL. A nitrogen index - total body protein normalized for body size - for diagnosis of protein status in health and disease. Nutr Res 1984; 4: 209-24.

24 Greenberg GR. Nutritional management of inflammatory bowel disease. Seminars in Gastrointestinal Disease 1993; 4: 69-86.

25 Jones VA. Comparison of total parenteral nutrition and elemental diet in induction of remission of Crohn's disease: long-term maintenance of remission by personalized food long-term maintenance of remission by pers

26 Teahon K, Smethurst P, Pearson M, Levi AJ, Bjarnason I. The effect of elemental diet on intestinal permeability and The effect of elemental diet on intestinal permeability and inflam.

27 Lochs H, Steinhardt HJ, Klaus-Wentz B, Zeitz M, Vegelsang $\mathrm{H}$, Sommer $\mathrm{H}$, et al. Comparison of enteral nutrition and drug treatment in active Crohn's disease. Gastroenterology 1991; 101: 881-8. 